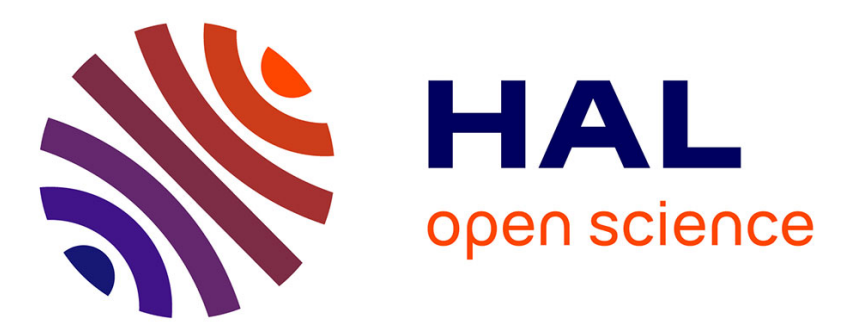

\title{
Indoor Air Quality Requirements in Green Building Certifications
}

\author{
Wenjuan Wei, Olivier Ramalho, Corinne Mandin
}

\section{To cite this version:}

Wenjuan Wei, Olivier Ramalho, Corinne Mandin. Indoor Air Quality Requirements in Green Building Certifications. Building and Environment, 2015, 92, pp.10-19. 10.1016/j.buildenv.2015.03.035 . hal02363627

\section{HAL Id: hal-02363627 \\ https://hal-cstb.archives-ouvertes.fr/hal-02363627}

Submitted on 14 Nov 2019

HAL is a multi-disciplinary open access archive for the deposit and dissemination of scientific research documents, whether they are published or not. The documents may come from teaching and research institutions in France or abroad, or from public or private research centers.
L'archive ouverte pluridisciplinaire HAL, est destinée au dépôt et à la diffusion de documents scientifiques de niveau recherche, publiés ou non, émanant des établissements d'enseignement et de recherche français ou étrangers, des laboratoires publics ou privés. 


\title{
Indoor Air Quality Requirements in Green Building Certifications
}

\author{
Wenjuan Wei, Olivier Ramalho, Corinne Mandin* \\ University of Paris-Est, Scientific and Technical Center for Building (CSTB), Health and \\ Comfort Department, French Indoor Air Quality Observatory (OQAI), 84 Avenue Jean Jaurès, \\ Champs sur Marne, 77447 Marne la Vallée Cedex 2, France \\ *Corresponding author: Centre Scientifique et Technique du Bâtiment (CSTB), Direction Santé- \\ Confort - Observatoire de la Qualité de l'Air Intérieur (OQAI), 84 Avenue Jean Jaurès, Champs \\ sur Marne, 77447 Marne la Vallée Cedex 2, France. Tel.: +331 6468 8597; fax: +331 64688823. \\ E-mail address: Corinne.MANDIN@cstb.fr
}

\begin{abstract}
Green building certifications aim to achieve sustainable buildings that are healthy, energysaving, and environmentally friendly. To construct healthy built environments for occupants, a high indoor environment quality (IEQ) has to be maintained. The goal of this paper is to analyze how and to what extent indoor air quality (IAQ), as a subset of IEQ, is taken into account in green building certifications worldwide. Thus, IAQ requirements were reviewed in 31 green building certifications from 30 countries worldwide. These certification programs include 13 countries in Asia, 9 in Europe, 5 in Americas, 2 in Oceania, and 1 in Africa. Fifty-five green building schemes were selected from among the 31 certifications. Rating systems are commonly used in green building schemes to evaluate the capability and level of a building to achieve lifecycle sustainability. The average contribution of IAQ to green building schemes worldwide is
\end{abstract}


7.5\%. Volatile organic compounds (VOCs), formaldehyde, and carbon dioxide $\left(\mathrm{CO}_{2}\right)$ are the indoor air pollutants most frequently considered. Ozone $\left(\mathrm{O}_{3}\right)$ and semi-volatile organic compounds (SVOCs) are mentioned in less than $6.7 \%$ of the certifications worldwide. Emission source control, ventilation, and indoor air measurement are the three main pathways used in green building schemes for IAQ management. All of the certifications include ventilation as a way to manage IAQ. Emission source control is included in $77 \%$ of the certifications and is mainly targeted at building material emissions. Indoor air measurement is included in $65 \%$ of the certifications but may be optional.

\section{Keywords}

Rating; green building; volatile organic compounds (VOCs); formaldehyde; sustainable building

\section{Introduction}

Green building, also known as sustainable building, is the practice of creating structures and using processes that are environmentally responsible and resource-efficient throughout a building's life-cycle ${ }^{[1]}$. "Green buildings" refer to the structures created using the principles and methodologies of sustainable construction ${ }^{[2]}$, which aim to construct energy-efficient, healthy, and productive buildings that reduce the significant impact of buildings on urban life and the global environment ${ }^{[3]}$. The history of green building design began in the late 1980 s when sustainability was defined by the United Nations' World Commission on Environment and Development ${ }^{[4]}$. Pioneering work on green building certification was achieved in the early 1990s 
in Europe and the United States, including the BRE Environmental Assessment Method (BREEAM) certification in the United Kingdom, Haute Qualité Environnementale (HQE) certification in France, and Leadership in Energy and Environmental Design (LEED) certification in the United States. Following these developments, many additional countries worldwide have joined the green building effort in the past two decades and have developed green building schemes adapted to national economic and environmental conditions.

To achieve sustainability in buildings, green building schemes usually include several categories. The LEED v4 scheme for building design and construction, for example, comprises location and transportation, sustainable sites, water efficiency, energy and atmosphere, materials and resources, indoor environmental quality, innovation, and regional priority ${ }^{[5]}$. The categories in the BREEAM scheme for new construction differ slightly from those used by LEED, comprising management, health and well-being, energy, transport, water, materials, waste, land use and ecology, pollution, and innovation ${ }^{[6]}$. Although the categories vary among different green building schemes, the schemes' detailed requirements share many similar traits.

Indoor environment quality has a significant impact on modern life around the globe. Americans, on average, spend approximately $90 \%$ of their time indoors ${ }^{[7]}$. Most of the time spent indoors occurs at home $(67 \% \text { on average for the French population })^{[8]}$. Indoor air pollutants, such as volatile organic compounds (VOCs), microbes, particles, etc., have negative effects on the health of indoor occupants. A number of studies on emission mechanism and health effect of indoor air pollutants have been carried out ${ }^{[9-11]}$. According to the "Guidelines for Air Quality" published by the World Health Organization (WHO), the main health effects of indoor air pollution include irritation, respiratory infection, and Sick Building Syndrome (SBS), among others. ${ }^{[12]}$ Hence, to 
guarantee the health of occupants in buildings, it is important to maintain high indoor air quality (IAQ).

The objectives of this paper are to review recent green building certifications and their schemes worldwide and to analyze how and to what extent IAQ is taken into account. The final goal is to provide a global overview of the IAQ sections included in the considered certifications and to identify possible means of improvement if relevant.

\section{Material and Methods}

2.1 Inventory and selection of green building certifications

To identify and select the green building certifications used in this study, three steps were carried out: (1) Search for green building certifications in scientific peer-reviewed literature, reference books, and on the Internet to include as many certifications as possible. International certifications that are applied in multiple countries, such as LEED, which applies in the USA, Mexico, Brazil, Argentina, Singapore and, until recently, India, are considered to be the same certification and are counted only once. (2) Access the official websites of the identified green building certifications and download the most recent free versions of schemes released within the past six years. For certifications that have different schemes for different types of buildings, e.g., new, existing, residential, and non-residential buildings, all the schemes are reviewed and considered as different requirements that are applied to different conditions in the certification. (3) Examine each scheme to see whether it has an IAQ section, and choose the final schemes for detailed analysis. Schemes for which a full-text version was not accessible or not free of charge were excluded. 
All the certifications have a section that evaluates IAQ. Ultimately, 31 certifications from 30 countries worldwide (13 in Asia, 9 in Europe, 5 in Americas, 2 in Oceania, and 1 in Africa) were retrieved, comprising 64 schemes that are applied to different types of buildings. Most of the green building schemes are written in English. The remaining schemes are written in the local language (e.g., French, Italian, and Chinese). Of the 64 schemes, one Vietnamese scheme was excluded because of language limitations, and eight other schemes were excluded because they were not accessible. A total of 55 schemes are reviewed in this paper, as shown in Table 1. The countries and certifications do not match one to one. Some countries, such as Canada and the United States, have several different green building certifications, and some certifications, such as LEED and BREEAM, are applied in multiple countries, as shown in Figure 1.

Table 1. Summary of the green building certifications and schemes considered

\begin{tabular}{lccc}
\hline & $\begin{array}{l}\text { No. of } \\
\text { countries/regions }\end{array}$ & $\begin{array}{l}\text { No. of } \\
\text { certifications }\end{array}$ & $\begin{array}{c}\text { No. of } \\
\text { schemes }\end{array}$ \\
\hline Asia & 13 & 13 & 30 \\
Europe & 9 & 9 & 14 \\
Americas & 5 & 5 & 7 \\
Oceania & 2 & 3 & 3 \\
Africa & 1 & 1 & 1 \\
SUM & 30 & 31 & 55 \\
\hline
\end{tabular}




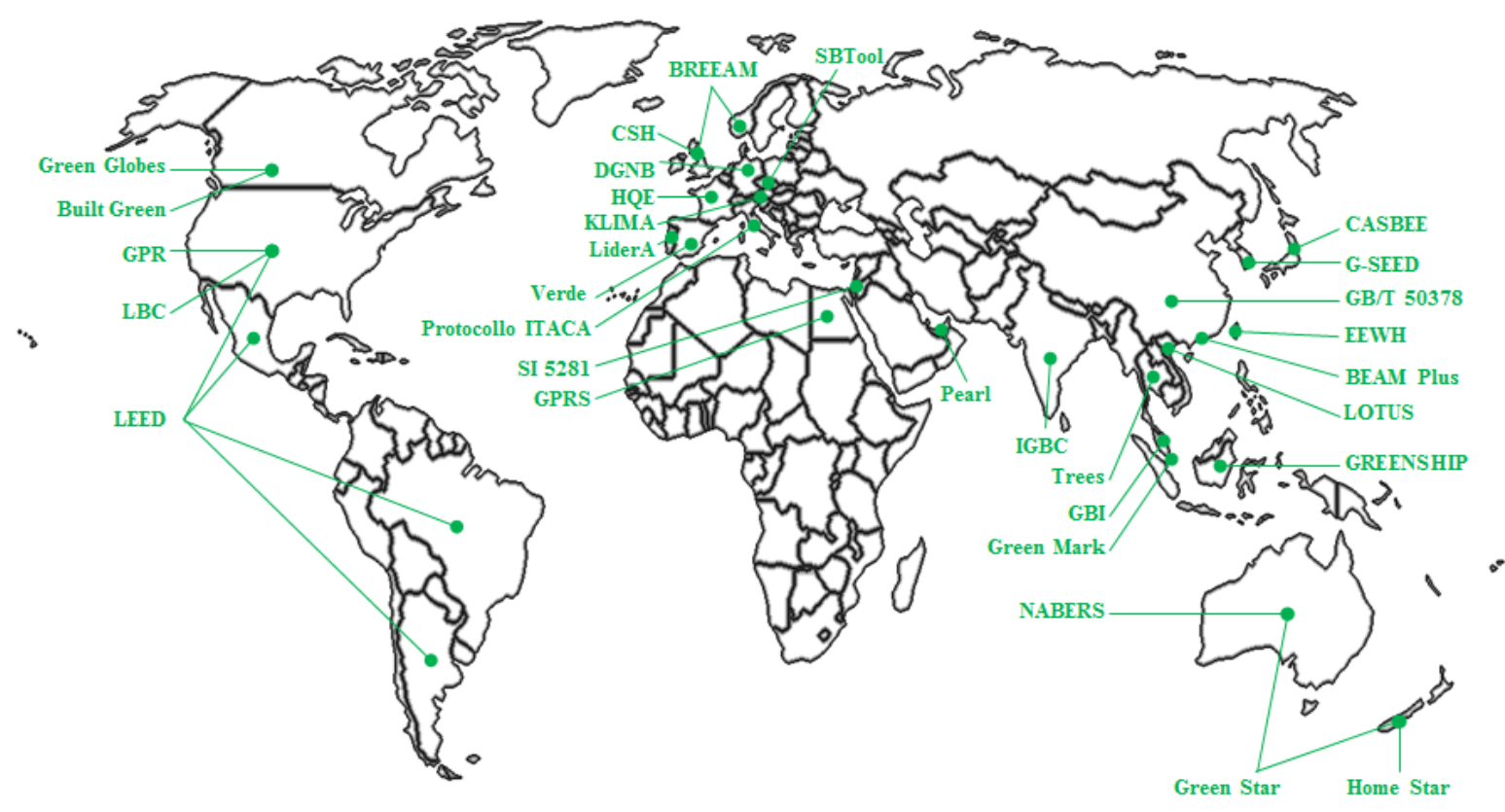

Figure 1. Green building certifications worldwide

\subsection{Green building schemes}

A green building scheme is a method used to evaluate sustainability during construction and/or throughout a building's life-cycle. Some certifications include different schemes designed to certify different types of buildings for design and/or performance. Two general methods are used to classify buildings into different types. One method is to classify buildings into two major categories, i.e., new buildings and existing buildings. New buildings include buildings that are under design, under construction, or recently completed. Existing buildings include buildings that are fully built, under repair, or under renovation. The other classification method categorizes buildings into non-residential and residential buildings. Non-residential buildings include offices, shopping malls, schools, etc. Residential buildings include apartments and houses. By combining the two methods, there are nine possible types of buildings, as shown in Table 2. A green 
building certification has at least one scheme that can be applied to one type of buildings. However, for most of the certifications, some different schemes apply to different types of buildings. Table 2 lists all the schemes identified in this study, according to the countries where the certifications are created or most commonly applied.

Table 2. Sources referenced for major green building schemes

\begin{tabular}{|c|c|c|c|c|c|c|c|c|c|c|}
\hline \multirow{2}{*}{$\begin{array}{l}\text { Key } \\
\text { countries }\end{array}$} & \multirow[b]{2}{*}{ Certification } & \multicolumn{3}{|l|}{ New } & \multicolumn{3}{|c|}{ Existing } & \multicolumn{3}{|c|}{ New \& existing } \\
\hline & & $\begin{array}{l}\mathrm{N}- \\
\mathrm{R}^{*}\end{array}$ & $\mathrm{R}^{* *}$ & $\begin{array}{l}\text { Both } \\
* * *\end{array}$ & N-R & $\mathrm{R}$ & Both & N-R & $\mathrm{R}$ & Both \\
\hline Japan & CASBEE & I & $\mathrm{Y}$ & 2010 & I & I & $\mathrm{Y}$ & l & $\mathrm{Y}$ & I \\
\hline China & GB/T 50378 & / & l & l & / & l & / & / & l & 2014 \\
\hline $\begin{array}{l}\text { Hong Kong } \\
\text { (China) }\end{array}$ & BEAM Plus & / & / & 2012 & / & / & 2012 & / & / & I \\
\hline Malaysia & GBI & 2009 & 2013 & l & 2011 & / & l & l & / & l \\
\hline Singapore & Green Mark & 2013 & 2013 & / & 2012 & 2011 & l & l & / & / \\
\hline Indonesia & GREENSHIP & l & / & 2014 & I & l & 2011 & / & / & l \\
\hline India & IGBC & / & l & 2014 & l & I & 2013 & 2009 & 2012 & l \\
\hline $\begin{array}{l}\text { South } \\
\text { Korea }\end{array}$ & G-SEED & / & l & l & l & l & l & 2013 & 2013 & l \\
\hline $\begin{array}{l}\text { Taiwan } \\
\text { (ROC) }\end{array}$ & EEWH & 2012 & 2012 & 2012 & 2012 & 2012 & 2012 & I & / & I \\
\hline Vietnam & LOTUS & I & I & I & / & l & Y & 2013 & 2011 & I \\
\hline
\end{tabular}




$\begin{array}{lllllllllll}\text { Israel } & \text { SI } 5281 & / & / & / & / & / & / & 2011 & / & / \\ \text { Thailand } & \text { Trees } & / & / & 2012 & / & / & / & / & / & / \\ \text { United } & & & & & & & & & & \\ \text { Arab } & \text { Pearl } & / & / & / & / & / & / & / & \mathrm{Y} & 2010\end{array}$

Emirates

\begin{tabular}{|c|c|c|c|c|c|c|c|c|c|c|}
\hline $\begin{array}{l}\text { No. Asia } \\
\text { (Reviewed) }\end{array}$ & $13(13)$ & $3(3)$ & 4(3) & $6(6)$ & $3(3)$ & $2(2)$ & 6(4) & $4(4)$ & $5(3)$ & $2(2)$ \\
\hline France & $\overline{\mathrm{HQE}}$ & 2013 & 2014 & 1 & 2014 & 1 & 1 & 1 & 1 & 1 \\
\hline UK & BREEAM & 2014 & I & I & I & 2012 & I & I & I & I \\
\hline UK & $\mathrm{CSH}$ & l & 2010 & I & I & l & I & I & I & I \\
\hline Germany & DGNB & 2012 & $\mathrm{Y}$ & I & $\mathrm{Y}$ & $\mathrm{Y}$ & I & I & I & I \\
\hline Italy & $\begin{array}{l}\text { Protocollo } \\
\text { ITACA }\end{array}$ & 2012 & 2012 & I & I & I & I & I & I & I \\
\hline Austria & KLIMA & 2014 & 2014 & I & I & I & I & I & I & I \\
\hline Portugal & LiderA & I & I & 2011 & I & I & I & I & I & I \\
\hline $\begin{array}{l}\text { Czech } \\
\text { Republic }\end{array}$ & SBTool & I & 1 & I & I & I & I & I & I & 2012 \\
\hline Spain & Verde & I & I & 2014 & I & I & I & I & I & I \\
\hline $\begin{array}{l}\text { No. Europe } \\
\text { (Reviewed) }\end{array}$ & $9(9)$ & $5(5)$ & 4(4) & $2(2)$ & $2(1)$ & $2(1)$ & & & & 1(1) \\
\hline USA & LEED & 2013 & 1 & 2014 & 1 & 1 & 2014 & 1 & 1 & 1 \\
\hline USA & GPR & I & I & I & I & I & I & I & 2014 & I \\
\hline USA & LBC & I & I & I & I & I & I & I & I & 2014 \\
\hline
\end{tabular}




\begin{tabular}{|c|c|c|c|c|c|c|c|c|c|c|}
\hline Canada & Green Globes & I & I & 2014 & I & I & Y & I & I & I \\
\hline Canada & Built Green & I & I & I & I & I & I & I & 2014 & I \\
\hline \multicolumn{11}{|l|}{ No. } \\
\hline Americas & $5(5)$ & 1(1) & & $2(2)$ & & & $2(1)$ & & $2(2)$ & 1(1) \\
\hline \multicolumn{11}{|l|}{ (Reviewed) } \\
\hline Australia & Green Star & I & I & 1 & 1 & 1 & 1 & 2009 & 1 & 1 \\
\hline Australia & NABERS & I & I & I & I & l & I & 2010 & Y & I \\
\hline New & & & & & & & & & & \\
\hline Zealand & Home Star & l & I & I & I & I & I & l & 2014 & I \\
\hline \multicolumn{11}{|l|}{ No. } \\
\hline Oceania & $3(3)$ & & & & & & & 2(2) & $2(1)$ & \\
\hline (Reviewed) & & & & & & & & & & \\
\hline Egypt & GPRS & I & I & 2011 & 1 & I & 1 & I & 1 & 1 \\
\hline $\begin{array}{l}\text { No. Africa } \\
\text { (Reviewed) }\end{array}$ & 1(1) & & & $1(1)$ & & & & & & \\
\hline SUM & & & & $11(1$ & & & & & & \\
\hline (Reviewed) & $31(31)$ & $9(9)$ & $8(7)$ & 1) & $5(4)$ & $4(3)$ & $8(5)$ & $6(6)$ & $9(6)$ & $4(4)$ \\
\hline
\end{tabular}

\footnotetext{
${ }^{*} \mathrm{~N}-\mathrm{R}$ : Non-residential buildings

${ }^{* *} \mathrm{R}$ : Residential buildings

${ }^{* * *}$ Both: Both non-residential and residential buildings

/: Resource not found

Y: Resource found but not accessible (e.g., not free of charge)
} 
20XX: Year of resource's most recent update

Within a scheme, several major categories are used for the evaluation, such as water efficiency, energy, and IEQ. This study focuses on the IAQ section, which includes the sources and species of indoor air pollutants, as well as methods that can be applied to maintain high IAQ. The IAQ section is typically included within the IEQ category, or sometimes in the health and well-being category. Related sections in green building IEQ schemes, such as thermal comfort, acoustic performance, and lighting/views, are not included in this study. 


\subsection{Scheme review method}

A total of 55 schemes were considered for the detailed review. There are two steps in the review procedure, as shown in Figure 2. In step 1, the objectives are to analyze how and to what extent IAQ is taken into account in green building certifications. IAQ sections and rating systems in green building schemes were reviewed. A statistical analysis was performed to quantitatively analyze the contribution of IAQ in green building certifications, as well as the target indoor air pollutants and the methods that are commonly employed for IAQ management. For certifications that have more than one scheme for different types of buildings, an average value is used to represent the contribution of IAQ. To analyze indoor air pollutants and IAQ management in different schemes within a certification, all the pollutants listed in the different schemes are combined, yielding the most comprehensive coverage of indoor air pollutants considered within the certification. In step 2, detailed analysis focuses on IAQ management. Methods and standards were reviewed to analyze the requirements for controlling the emission sources of indoor air pollutants, as well as those for ventilation and indoor air measurement. For certifications with more than one scheme for different types of buildings, all the IAQ management methods are considered together when discussing the methods used to maintain high IAQ. 


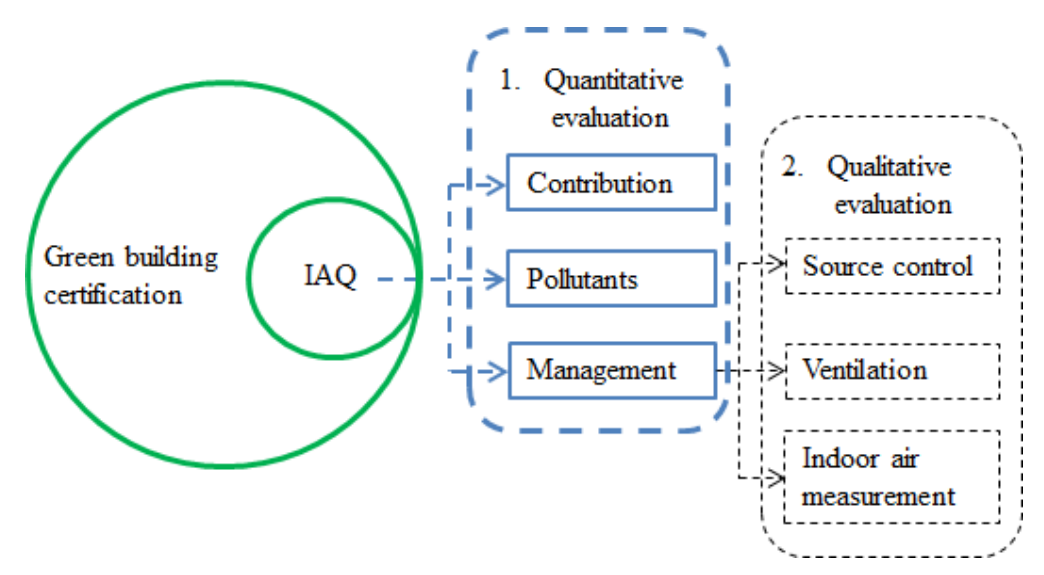

Figure 2. Review procedure for the IAQ section within certifications

\section{Results}

\subsection{Contribution of IAQ in green building certifications}

\subsubsection{Rating methods in green building schemes}

Rating systems are universally used in green building schemes. To achieve building sustainability, the requirements can be divided into several categories, such as energy efficiency, water, and health. In each category, there are several sections, such as IAQ, lighting, and thermal comfort. In each section, several requirements are defined in detail. For each requirement in a green building scheme, a scoring system is used to evaluate to what extent the requirement is achieved. The total final score represents the life-cycle sustainability of the building and is calculated after all the requirements in the scheme are evaluated. Therefore, the total final score is a function of the scores in the respective categories, sections, and requirements, as shown in Equations (1) - (3). 
Final $=f_{1}\left((\text { Category })_{1}, \ldots,(\text { Category })_{n}\right), n=1,2,3, \ldots$

$(\text { Category })_{n}=f_{2}\left((\text { Section })_{1}, \ldots,(\text { Section })_{m}\right), n=1,2,3, \ldots ; m=1,2,3, \ldots$

$(\text { Section })_{m}=f_{3}\left((\text { Requirement })_{1}, \ldots,(\text { Requirement })_{i}\right), m=1,2,3, \ldots ; i=1,2,3, \ldots$

In general, three types of rating methods are used to calculate the total final score. The first approach is a point-based scoring method, such as in LEED. In this case, scores are assigned as points. Each requirement earns a certain number of points depending on how it is fulfilled. The total final score is defined by the number of requirements that are met and the corresponding sum of all points earned. For this method, Equations (1) - (3) are redefined as Equations (4) - (6).

Final $=\sum_{1}^{n}(\text { Category })_{n}, n=1,2,3, \ldots$

$(\text { Category })_{n}=\sum_{1}^{m}(\text { Section })_{m}, n=1,2,3, \ldots ; m=1,2,3, \ldots$

$(\text { Section })_{m}=\sum_{1}^{i}(\operatorname{Re} \text { quirement })_{i}, m=1,2,3, \ldots ; i=1,2,3, \ldots$

The second rating method is a weighted approach, such as in BREEAM and NABERS. Points are assigned to each requirement to evaluate to what extent it has been fulfilled. For each category, the score is the ratio of the points achieved and the maximum points available in the category, represented as a percentage. For example, the score in a category is 100 if all the requirements in the category are met. Different weighting values are employed for the categories 
to indicate their non-uniform importance when calculating the total final score. For this method, Equations (1) - (3) are redefined as Equations (7) - (9).

$$
\begin{aligned}
& \text { Final }=\sum_{1}^{n}\left((\text { Category })_{n} \times(\text { Weighting })_{n}\right), n=1,2,3, \ldots \\
& (\text { Category })_{n} \%=\frac{\sum_{1}^{m}(\text { Section })_{m}}{(\text { MAXpo int } s)_{n}} \%, n=1,2,3, \ldots ; m=1,2,3, \ldots \\
& (\text { Section })_{m}=\sum_{1}^{i}(\operatorname{Re} \text { quirement })_{i}, m=1,2,3, \ldots ; i=1,2,3, \ldots
\end{aligned}
$$

The third rating method comprises additional evaluations that are more complicated or unique. These evaluations vary among green building schemes and are thus difficult to summarize.

Among the 31 certifications, 12 use a point-based scoring method, 8 use a weighted method, and 4 use other, more complicated calculation methods. Finally, there are 7 certifications in which the rating systems are not clear because some categories or sections that are not relevant to IAQ are missing from the download schemes.

Buildings can be certified at different levels. There are 4 levels in LEED certification, i.e., Certified, Silver, Gold, and Platinum. There are 6 levels in BREEAM certification, i.e., Unclassified, Pass, Good, Very good, Excellent, and Outstanding. The levels of green building certification are mainly based on the total final score. Veto requirements in some categories are also commonly introduced in addition to the total final score to determine the level of certification. Veto requirements are not consistent across different green building schemes and are thus not discussed in further detail here. 


\subsubsection{Contribution of IAQ to green building certifications}

IAQ is taken into account in all of the retrieved green building certifications. The contribution of IAQ to a green building scheme can be quantified if the first or second rating methods are used to calculate the total final score. For the first (point-based) rating method, the contribution of IAQ to the green building scheme is the ratio of the maximum points in the IAQ section to the maximum total final points. For the second (weighted) rating method, the contribution of IAQ to the green building scheme is the ratio of the maximum score in the IAQ section to the maximum total final score.

The average contribution of IAQ to the 20 point-based or weighted green building certifications worldwide is $7.5 \%$, as shown in Figure 3. In general, American green building certifications place more emphasis on IAQ compared with systems used in other countries. The average contribution of IAQ to American green building certifications is $9.4 \%$. However, the highest contribution of IAQ worldwide is $10.6 \%$ for Tree certification in Thailand. The highest contribution of IAQ to European certifications is $10 \%$ for KLIMA certification in Austria.

Among the 20 point-based or weighted certifications, 8 include different contributions of IAQ within their respective schemes, as shown in Table 3. Nevertheless, these different contributions retain the same order of magnitude. 


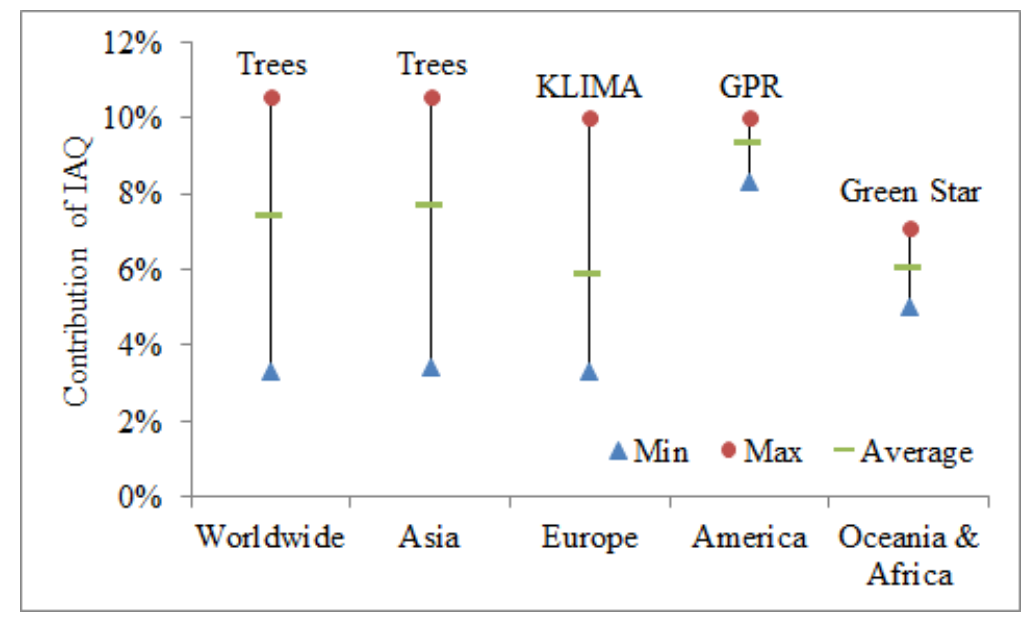

Figure 3. Contribution of IAQ in green building certifications by continent.

Table 3. Contributions of IAQ in different green building schemes

\begin{tabular}{lccccccccc}
\hline \multirow{2}{*}{ Certification } & \multicolumn{3}{c}{$\mathrm{New}$} & \multicolumn{3}{c}{ Existing } & \multicolumn{2}{c}{ New \& existing } \\
\cline { 2 - 8 } & $\mathrm{N}-\mathrm{R}^{*}$ & $\mathrm{R}^{* *}$ & Both $^{* * *}$ & $\mathrm{~N}-\mathrm{R}$ & $\mathrm{R}$ & Both & $\mathrm{N}-\mathrm{R}$ & $\mathrm{R}$ & Both \\
\hline GBI & $6 \%$ & $6 \%$ & $/$ & $10 \%$ & $/$ & $/$ & $/$ & $/$ & $/$ \\
Green Mark & $2.1 \%$ & $2.6 \%$ & $/$ & $5.6 \%$ & $0 \%$ & $/$ & $/$ & $/$ & $/$ \\
GREENSHIP & $/$ & $/$ & $6 \%$ & $/$ & $/$ & $12.8 \%$ & $/$ & $/$ & $/$ \\
IGBC & $/$ & $/$ & $8 \%$ & $/$ & $/$ & $6 \%$ & $9 \%$ & $9 \%$ & $/$ \\
G-SEED & $/$ & $/$ & $/$ & $/$ & $/$ & $/$ & $9.3 \%$ & $9.2 \%$ & $/$ \\
LOTUS & $/$ & $/$ & $/$ & $/$ & $/$ & $/$ & $7.8 \%$ & $7.7 \%$ & $/$ \\
KLIMA & $10 \%$ & $10 \%$ & $/$ & $/$ & $/$ & $/$ & $/$ & $/$ & $/$ \\
LEED 2009 & $9.1 \%$ & $/$ & $8.2 \%$ & $/$ & $/$ & $8.2 \%$ & $/$ & $/$ & $/$ \\
\end{tabular}

\footnotetext{
${ }^{*}$ N-R: Non-residential buildings

${ }^{* *} \mathrm{R}$ : Residential buildings
} 
*** Both: Both non-residential and residential buildings

3.2 Indoor air pollutants in green building certifications

A statistical analysis was performed to summarize the indoor air pollutants that are taken into account in green building certifications worldwide, as shown in Figure 4. In three certifications (EEWH, Protocollo ITACA, and Home Star), no specific indoor air pollutant is targeted. The top 3 indoor air pollutants that are most frequently considered worldwide are VOCs, formaldehyde, and carbon dioxide $\left(\mathrm{CO}_{2}\right)$. VOCs are taken into account in $26(84 \%)$ of the green building certifications. In 21 certifications, VOCs are used to represent indoor chemical pollutants in general, and no specific compounds are identified in the category. In 5 certifications (CASBEE, LEED, GB/T 50378, HQE, and IGBC), VOC species are listed in detail, including compounds such as benzene and toluene. $\mathrm{CO}_{2}$ is considered an indoor pollutant in $65 \%$ of the certifications. Asbestos pollution is taken into account in $45 \%$ of the certifications, not only for existing buildings but also for new construction. Microbes, such as fungi and bacteria, are considered in $32 \%$ of the certifications. The control of indoor airborne particle $\left(\mathrm{PM}_{10}\right.$ or $\left.\mathrm{PM}_{2.5}\right)$ concentrations is proposed in $16 \%$ of the certifications. 


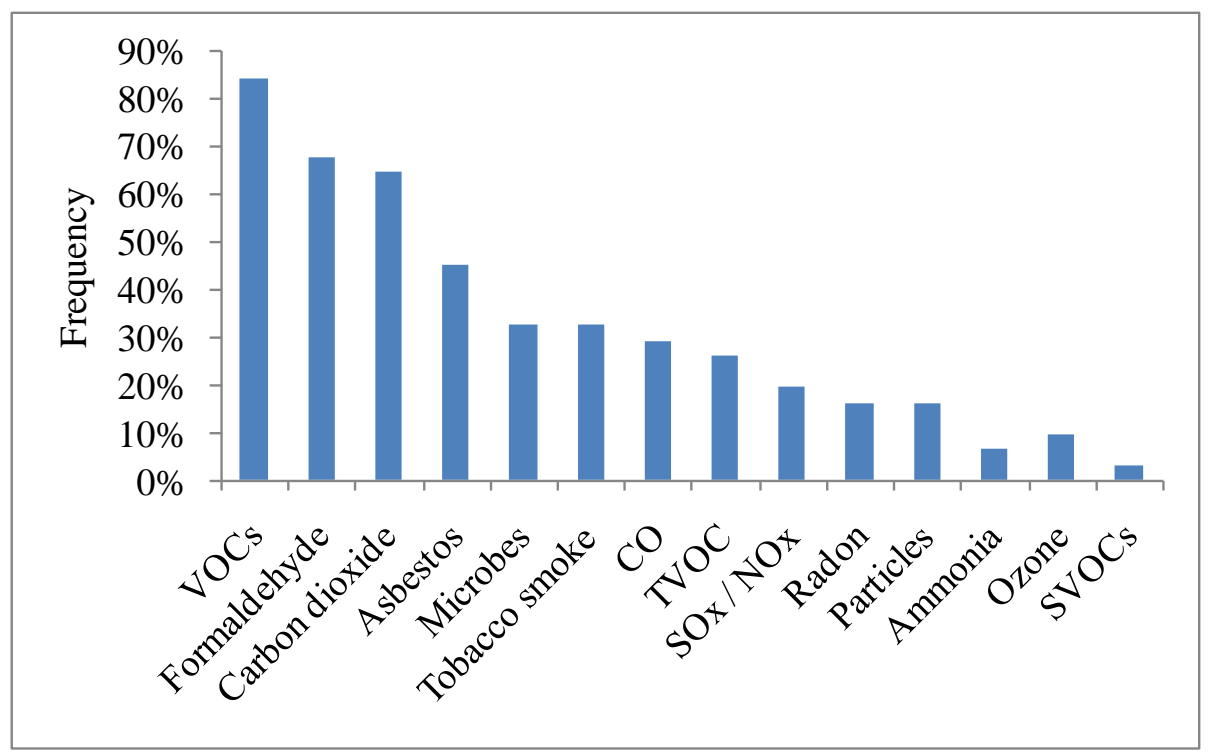

Figure 4. Frequency of indoor air pollutants in green building certifications worldwide

Green building certifications in Europe, Asia, Americas, Oceania, and Africa place different amounts of emphasis on target indoor air pollutants. Figure 5 shows the indoor air pollutants considered in green building certifications by continent. Among chemical pollutants, $80 \%$ of the green building certifications in Americas consider formaldehyde as a target indoor air pollutant, compared with $44 \%$ in Europe. A total of $44 \%$ of the green building certifications in Europe are interested in indoor total VOC (TVOC) concentrations, compared with $15 \%$ in Asia. Ozone is not mentioned in certifications in Oceania or Africa. Semi-volatile organic compounds (SVOCs) are only mentioned in the KLIMA certification in Austria. Asbestos is taken into account in 56\% of the European certifications, compared with $25 \%$ in Oceania and Africa. Radon is not considered in Oceania or Africa. Finally, regarding biological contamination, green building certifications in Oceania and Africa, as well as in Asia, pay more attention to indoor microbes 
(50\% and 38\%, respectively) compared with the certifications in Europe and Americas (22\% and $20 \%$, respectively).

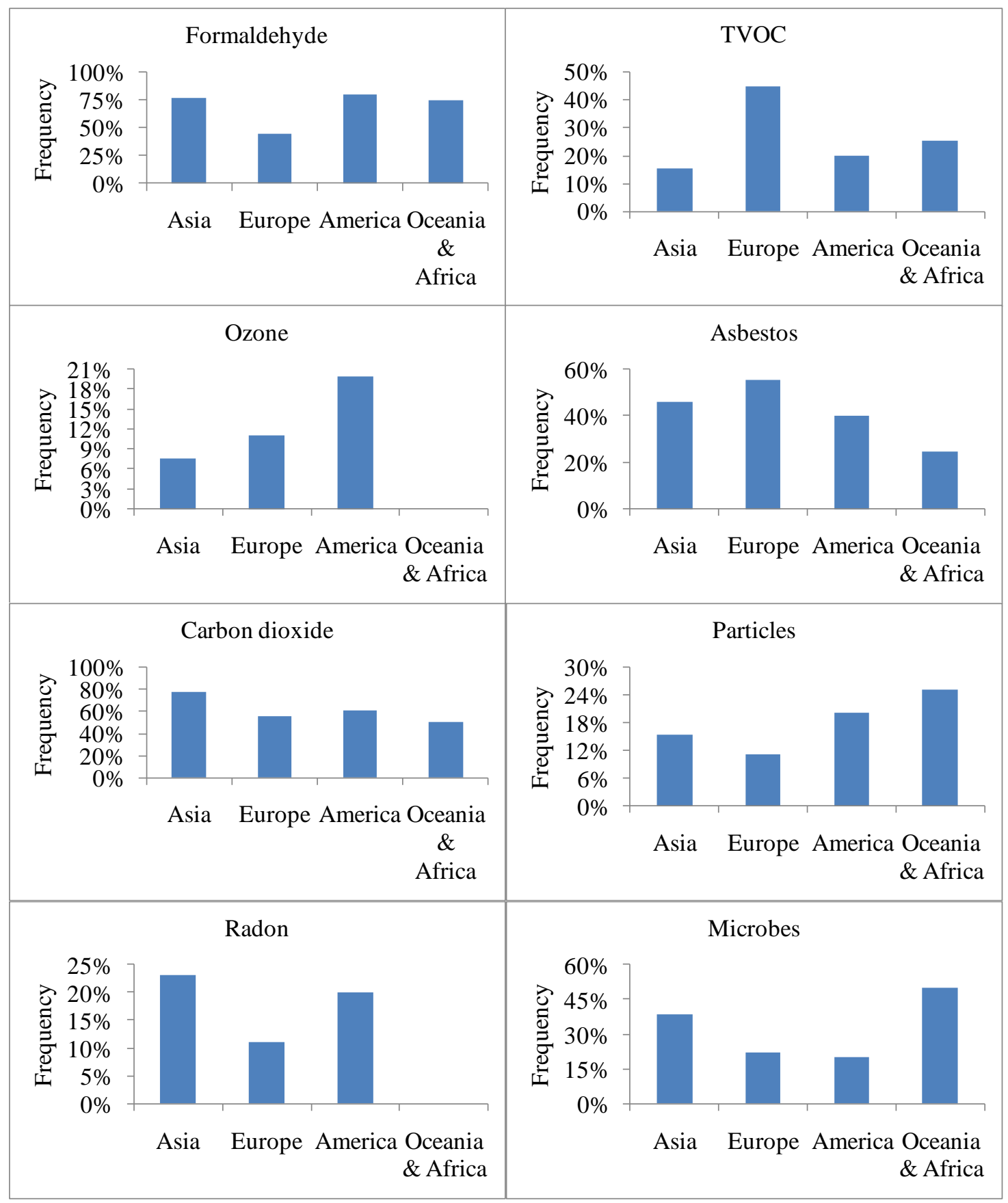

Figure 5. Frequency of target indoor pollutants in certifications by continent 


\subsection{IAQ management}

To manage IAQ, three pathways are preferred in green building schemes, i.e., emission source control, ventilation, and indoor air measurement. The three pathways focus on different periods of a building's life-cycle. Emission source control aims at designing and choosing low-emission indoor materials, e.g., paint, carpets and flooring, and furniture, for indoor construction and renovation. The goal of ventilation is to provide an appropriate indoor/outdoor air exchange rate to maintain high IAQ. Indoor air measurement is used to check whether indoor concentrations comply with given thresholds and thus to monitor the efficiency of emission source control methods and ventilation. Indoor air measurement can take place in new buildings before or after indoor occupancy. The pollutants measured include chemical pollutants and particulate matter.

The occurrence frequencies of the three pathways proposed in green building certifications are shown in Figure 6. All of the certifications propose ventilation for IAQ management, whereas $77 \%$ and $65 \%$ of the certifications propose emission source control and indoor air measurement, respectively. Certifications in Asian and American countries typically include emission source control requirements. Indoor air measurement is most commonly proposed in European and American certifications. 


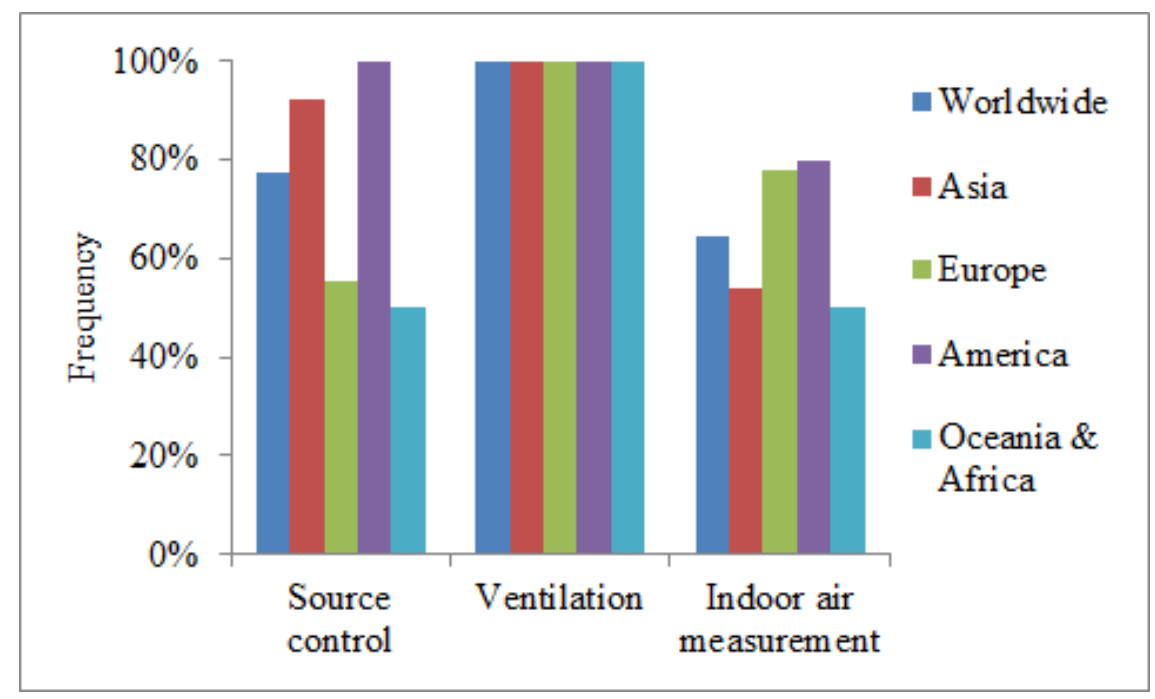

Figure 6. IAQ management in green building certifications

\subsubsection{Emission source control of indoor pollutants}

Emission source control of indoor pollutants, proposed in $77 \%$ of the certifications, aims at designing and choosing low-emission materials. For paint and carpets, the target pollutants are mainly VOCs. There are two options that allow building materials to be considered low-VOCemission materials in green building schemes. For the first option, materials must have thirdparty green material certifications to be considered low-VOC-emission materials in green building schemes. Such third-party certifications are usually national certifications; acceptable third-party certifications vary widely among different green building certifications. For the alternative option, materials or products must have VOC contents achieving the threshold level mentioned in the green building schemes, as shown in Table 4, or of compliance with other emissions and content standards such as European Directive 2004/42/CE: 2004 and ANSI/BIFMA e3-2011. Low-formaldehyde-emission products are recommended in green 
building schemes for wooden materials, such as medium-density board, wooden flooring, etc. European green building certifications recommend low-formaldehyde-emission wooden-based panels that are labeled E1 according to ENV 717-1 (2004). In other countries, such as USA, wooden products that do not contain urea-formaldehyde resin are required. Government efforts are important for reducing formaldehyde emission as well as influencing green building schemes. In Japan, reducing the emission of chemical pollutants from building materials is mandatory and included in the national Building Standards Law.

Table 4. Threshold level of VOC contents in building materials $(\mathrm{g} / \mathrm{L})$

\begin{tabular}{lccc}
\hline & IGBC & Pearl & Trees \\
\hline Paints \& Coatings & $50-350$ & $30-750$ & 250 \\
Adhesives \& Sealants & $30-100$ & & \\
& & & \\
\hline
\end{tabular}

To reduce the exposure of building occupants to hazardous chemicals via indoor pollutants, LEED and IGBC emission source control methods for existing buildings aim not only at choosing low-VOC-emission building materials but also at choosing sustainable cleaning products or equipment. In LEED certification, the requirement includes either a green clean policy involving the purchasing of cleaning products, materials, and equipment, or a green clean service certified under Green Seal or International Sanitary Supply Association (ISSA) Cleaning Industry Management standards. IGBC certification requires that the purchase of eco-friendly 
housekeeping chemicals procured in the past year meet the Green Seal standard (GS-37) or other Indian/European equivalent standards.

\subsubsection{Ventilation}

All of the certifications worldwide include requirements for ventilation. Mechanical or natural means of ventilation are offered as options in most of the green building certifications. Detailed requirements for ventilation vary greatly among different schemes. International standards are commonly referenced in green building schemes. As shown in Figure 7, 39\% of the green building certifications examined here preferentially use the ASHRAE 62.1 standard to specify minimum ventilation rates. A total of $23 \%$ of the green building certifications, mostly in European countries, rely on EN 15251 and EN 13779 standards. Other certifications, such as Green Star and Green Mark, use local ventilation standards for the design of ventilation.

Some certifications include additional requirements related to outdoor air intake and the filters used in ventilation systems to prevent gaseous and particulate pollutants from entering the building; these requirements are listed in Table 5. 


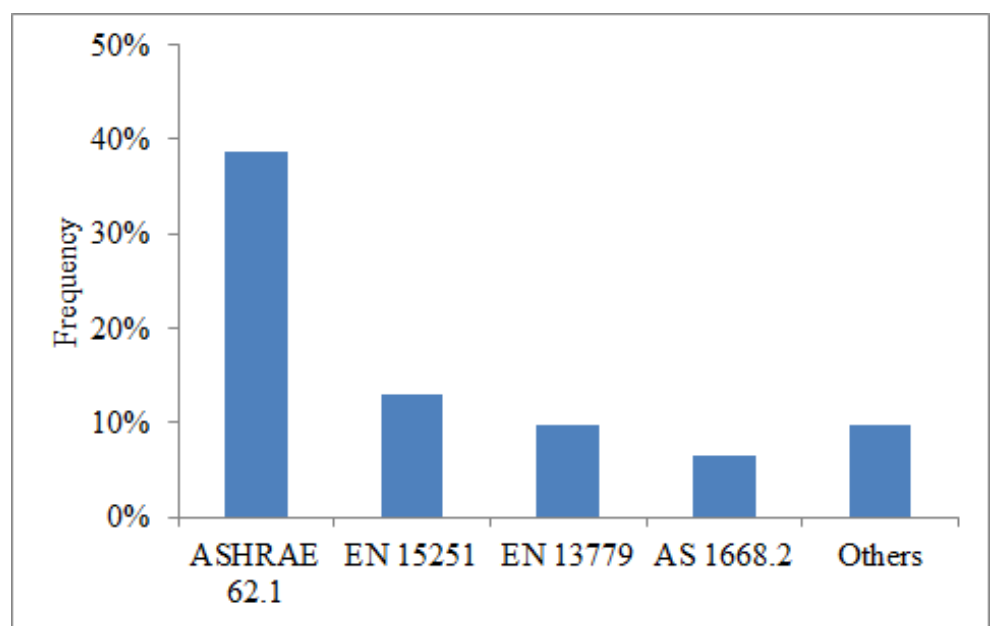

Figure 7. Standards for ventilation management in green building certifications worldwide

Table 5. Requirements for outdoor air intake and ventilation system filters

\section{Certification Requirements}

CASBEE $\quad$ Air intakes must be located away from sources of pollution.

IGBC Outdoor air intakes must be located a minimum of $7.6 \mathrm{~m}$ from outdoor smoking areas;

Install air filtering media after building flush-out, using at least MERV 13, EU 7 or equivalent.

SI $5281 \quad$ Building's air intakes and exhausts must be more than $10 \mathrm{~m}$ apart;

If a source of external pollution exists, the ventilation system must filter the air.

Pearl Separation distances required between outdoor air intakes and any exhausts or discharge points;

Establish 25-m smoke-free zones around outdoor air intakes; 
Outdoor air intakes must be placed away from known sources of pollution;

Installation of MERV 8 or G4 class filters in each return air grille.

BEAM Plus Air intakes are sited away from pollutant sources and avoid short-circuiting with exhausts;

Filters are effective in removing outdoor pollutants.

BREEAM Building's air intakes and exhausts are more than $10 \mathrm{~m}$ apart, and intakes are more than $20 \mathrm{~m}$ from sources of external pollution.

LEED Each ventilation system that supplies outdoor air to occupied spaces must have particle filters;

Filtration medias are installed at each return air grille and return or transfer duct inlet opening to avoid bypass around the filtration media.

Green Exhaust outlets and plumbing vent stacks located at least $6 \mathrm{~m}$ away from outdoor Globes air intakes;

Outdoor air intakes located at least $9 \mathrm{~m}$ away from sources of pollution; Outdoor air intakes protected with $6.4 \mathrm{~mm}$ or smaller mesh screens.

GPRS Separation distances required between outdoor air intakes and any exhausts or discharge points;

Outdoor air intakes are located a minimum of $25 \mathrm{~m}$ from outdoor smoking areas.

\subsubsection{Indoor air measurement}

Indoor air measurement can take place before or during indoor occupancy, depending on the certification. There are 20 green building certifications comprising 25 schemes that propose indoor air measurement. In 21 schemes, such as GB/T 50378, IGBC, and NABERS, indoor air 
measurement is mandatory but to varying degrees. Assessment points for indoor air measurement can be guaranteed only if the results of measurements meet requirements. In the other 4 schemes, including LEED, HQE, and BREEAM, indoor air measurement is optional due to the presence of alternative options for managing IAQ or depending on the level of certification. In the schemes that propose indoor air measurement, the thresholds of IAQ pollutants vary depending on the level of certification. Five pollutants of concern are indicated on every continent: $\mathrm{CO}_{2}$, formaldehyde, TVOCs, $\mathrm{CO}$, and $\mathrm{PM}_{10}$, as shown in Figure 8. On average, three parameters are measured in each certification.

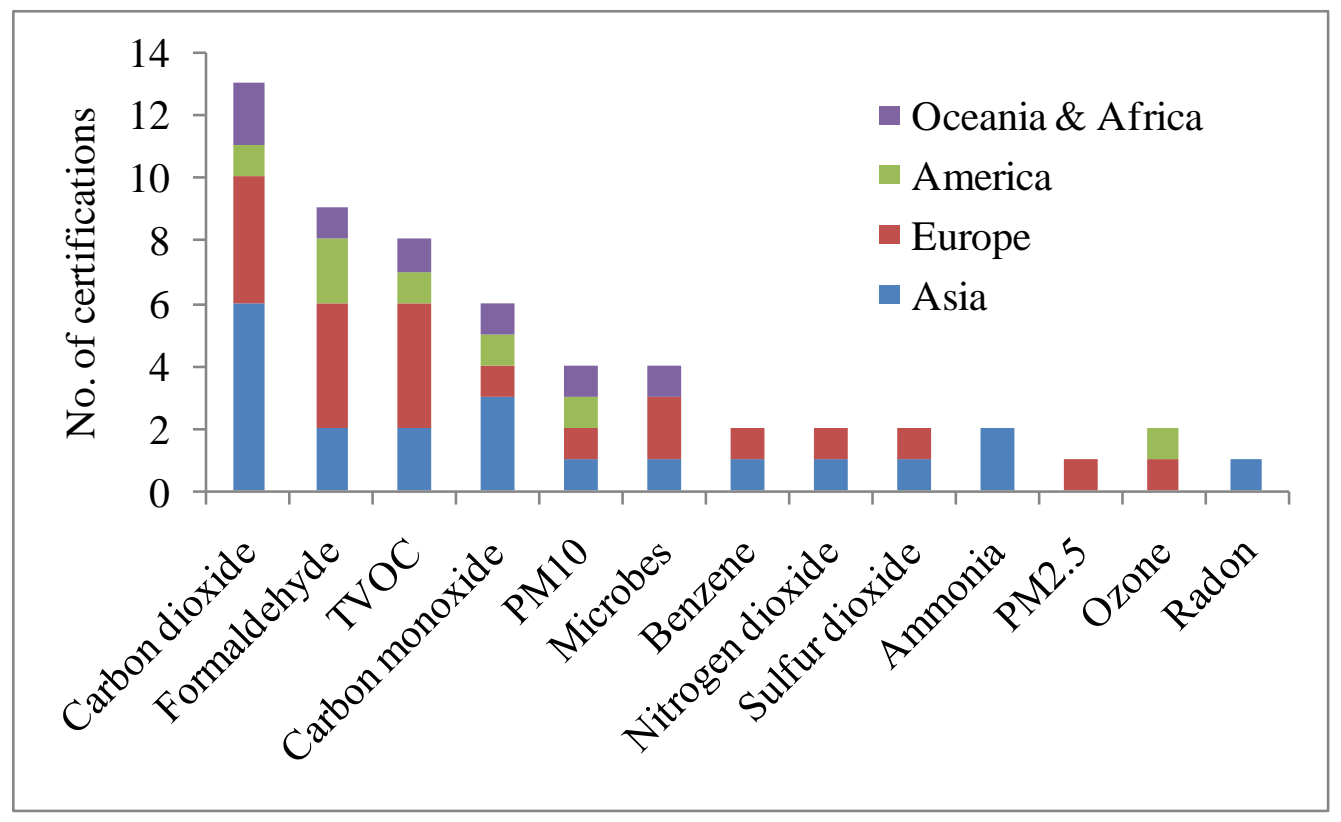

Figure 8. Indoor air pollutants targeted for indoor air measurement

Indoor air sampling strategies are not mentioned in detail in most of the certifications that propose indoor air measurement. Detailed information is provided in seven out of the twenty 
certifications (LEED, IGBC, BEAM Plus, HQE, BREEAM, KLIMA, and NABERS). Sampling strategies vary among the certifications. In general, the number and location of sampling points depend on the size of the building and must represent "normal" occupied spaces. Table 6 shows the details of sampling strategies used in different certifications.

Table 6. Indoor air sampling strategies in certifications for which detailed information is provided

Certification Indoor air sampling strategy

LEED Conduct all measurements before occupancy but during normal occupied hours, with the building ventilation system started at the normal daily start time and operated at the minimum outdoor airflow rate for the occupied mode throughout the test;

Use current versions of ASTM standard methods, EPA compendium methods, or ISO methods;

Laboratories that conduct the tests for chemical analysis of formaldehyde and VOCs must be accredited under ISO/IEC 17025 for the test methods they use;

Retail projects may conduct the testing within 14 days of occupancy.

IGBC Same as LEED.

BEAM Plus Samples collected at the lowest outdoor air intake location.

HQE Sampling devices are in the centers of rooms, or at a distance of at least $50 \mathrm{~cm}$ from the walls.

BREEAM Measurements are taken prior to occupancy; 
Samples are taken in representative habitable or occupiable rooms with ventilation and heating systems on.

KLIMA Random checking of IAQ in rooms, maximum 50 sampling points.

NABERS Prescriptive methodology for existing office buildings including areas, locations, and instruments, based on ISO 17025 certification for the entire building and occupied time;

Number of sampling locations depends on the size of the building and number of ventilation systems.

Detailed information on how to measure indoor air pollutants is usually not included in green building schemes. For $\mathrm{CO}_{2}$ and $\mathrm{CO}$, continuous monitoring devices are commonly used. For other compounds, it is not clear whether active sampling or passive sampling is recommended. No common international standard on indoor air pollutant measurements exists for all certifications. However, five out of the nine certifications that propose the measurement of indoor formaldehyde concentrations follow the ISO 16000-3 standard, and four out of the eight certifications that propose the measurement of indoor TVOC concentrations follow the ISO 16000-6 standard; these standards are summarized in Table 7. ISO 16000-3 is suitable for the determination of formaldehyde in the approximate concentration range from $1 \mu \mathrm{g} / \mathrm{m}^{3}$ to $1 \mathrm{mg} / \mathrm{m}^{3}$. The measurement procedure involves active sampling of formaldehyde from air on adsorbent cartridges coated with 2,4-dinitrophenylhydrazine (DNPH), followed by subsequent analysis using high-performance liquid chromatography (HPLC) ${ }^{[13]}$. ISO 16000-6 is suitable for the determination of VOCs in indoor air. The measurement procedure involves active sampling of 
VOCs from air on Tenax TA sorbent with subsequent thermal desorption (TD) and gas chromatographic (GC) analysis ${ }^{[14]}$.

Table 7. Standards and methods used to measure indoor formaldehyde and TVOC concentrations

\begin{tabular}{|c|c|c|c|c|}
\hline Pollutant & ISO 16000-3 & ISO 16000-6 & GB/T 18883 & Other protocols \\
\hline \multirow[t]{7}{*}{ Formaldehyde } & LEED & / & GB/T 50378 & HQE: HQE Performance \\
\hline & BREEAM & & & Working Group; \\
\hline & DGNB & & & KLIMA: ISO 16000-2 \& EN \\
\hline & IGBC & & & 717-1; \\
\hline & NABERS & & & GPR: Not mentioned; \\
\hline & & & & NABERS: By accredited \\
\hline & & & & assessor. \\
\hline \multirow[t]{6}{*}{ TVOC } & & LEED & GB/T 50378 & HQE: HQE Performance \\
\hline & & BREEAM & & Working Group; \\
\hline & & DGNB & & KLIMA: ISO 16000-5 \& \\
\hline & & IGBC & & ONORM M 5700-2; \\
\hline & & & & NABERS: ISO 16200-1, by \\
\hline & & & & accredited assessor. \\
\hline
\end{tabular}

Measured indoor air pollutant concentrations are usually compared with threshold values. The ranges of these concentration thresholds reported in the considered green building schemes are shown in Table 8. The concentration thresholds of indoor air pollutants may vary among 
certifications according to different rating points (DGNB) or exposure times (HQE). According to WHO guidelines for IAQ, a short-term (30-minute) guideline of $100 \mu \mathrm{g} / \mathrm{m}^{3}$ is recommended for indoor formaldehyde concentrations to prevent sensory irritation in the general population ${ }^{[15]}$. Therefore, indoor formaldehyde concentrations in the green buildings that are certified at higher levels might not achieve the WHO guideline.

Table 8. Concentration thresholds of indoor air pollutants used in green building certifications

\begin{tabular}{lll}
\hline Pollutant & Threshold range & Certification \\
\hline Formaldehyde & $10-120 \mu \mathrm{g} / \mathrm{m}^{3}$ & IGBC, HQE, BREEAM, DGNB, KLIMA, \\
& & LEED, NABERS \\
TVOC & $300-25000 \mu \mathrm{g} / \mathrm{m}^{3}$ & IGBC, HQE, BREEAM, DGNB, KLIMA, \\
& & LEED, NABERS \\
Benzene & $2-5 \mu \mathrm{g} / \mathrm{m}^{3}$ & HQE \\
& & \\
$\mathrm{PM}_{10}$ & $20-50 \mu \mathrm{g} / \mathrm{m}^{3}$ & IGBC, HQE, LEED, NABERS \\
$\mathrm{PM}_{2.5}$ & $10-25 \mu \mathrm{g} / \mathrm{m}^{3}$ & HQE, LEED \\
$\mathrm{CO}_{2}$ & $530-1500 \mathrm{ppm}$ & GREENSHIP, IGBC, Pearl, KLIMA, \\
& & GPRS, NABERS \\
$\mathrm{CO}^{10-100000 \mu \mathrm{g} / \mathrm{m}^{3}}$ & GREENSHIP, IGBC, HQE, NABERS \\
& exposure per 8 hours, & \\
$\mathrm{NO}_{2}$ & or $+2 \mathrm{ppm} \mathrm{over} \mathrm{outside}$ & \\
& $40-5600 \mu \mathrm{g} / \mathrm{m}^{3}$ & GREENSHIP, HQE
\end{tabular}




$\begin{array}{lll}\mathrm{SO}_{2} & 20-5200 \mu \mathrm{g} / \mathrm{m}^{3} & \text { GREENSHIP, HQE } \\ \text { Ammonia } & 17000 \mu \mathrm{g} / \mathrm{m}^{3} & \text { GREENSHIP } \\ \text { Microbes } & \text { Indoor/outdoor }=1 & \text { NABERS }\end{array}$

\section{Discussion}

\subsection{Limitations of the analysis}

Although the existing certifications were inventoried as exhaustively as possible, some certifications may be missing. Certifications that lack an English translation and are not mentioned in English-language publications are unlikely to be found. In general, most of the certifications reported in this study are written in English. Others are written in French, German, Italian, Spanish, Chinese, Indonesian, and Thai. There may exist certifications written in other languages that are missing from this study. In addition, green building certifications that are not accessible online or are not free of charge are not included in this study for practical reasons. Moreover, green building schemes that provide only a brief summary of IAQ and other sections or those that do not provide a full text regarding IAQ are not included in this study. This study shows the need for transparency to allow the comparison and normalization of green building schemes worldwide.

\subsection{Target indoor air pollutants}

Indoor air pollutants that are taken into account in WHO ambient and indoor air guidelines include $\mathrm{SO}_{2}$, airborne particles, $\mathrm{NO}_{x}, \mathrm{CO}, \mathrm{CO}_{2}$, water vapor, mold spores, radon, pollen, lead, 
manganese, cadmium, mercury, arsenic, asbestos, ammonia, ozone, nicotine, acrolein, allergens, viable organisms, VOCs, polycyclic aromatic hydrocarbons (PAHs), formaldehyde, benzene, naphthalene, trichloroethylene, and tetrachloroethylene ${ }^{[12,15,16]}$. The pollutants in the WHO guidelines that are also considered in green building certifications include $\mathrm{SO}_{2}, \mathrm{NO}_{\mathrm{x}}, \mathrm{CO}, \mathrm{CO}_{2}$, radon, asbestos, ammonia, ozone, nicotine, VOCs, formaldehyde, benzene, and particulate matter. Thus, most of the priority compounds are considered in the studied certifications.

Ozone, known as a reactive chemical, can react with human skin lipids and generate carbonyl, carboxyl, and $\alpha$-hydroxy ketone ${ }^{[17]}$. Photocopiers and printers in offices are known to emit ozone during use. However, indoor ozone contamination is only taken into account in LEED, BEAM Plus and HQE certifications. Given the negative health effects of this compound, the regulation of ozone via indoor emission source control and measurement in green building certifications might need to be improved in the future.

Indoor particle pollution varies from country to country and from region to region. Indoor particle control is required in four certifications (BEAM Plus, IGBC, HQE, and LEED). BEAM Plus certification mainly focuses on outdoor particle source control, whereas the other three certifications require measurements of indoor $\mathrm{PM}_{10}$ concentrations. $\mathrm{PM}_{2.5}$ concentrations are measured in HQE and LEED certifications. The thresholds of $\mathrm{PM}_{2.5}$ concentrations in indoor air are $10 \mu \mathrm{g} / \mathrm{m}^{3}$ annually or $25 \mu \mathrm{g} / \mathrm{m}^{3}$ daily in the HQE scheme and $15 \mu \mathrm{g} / \mathrm{m}^{3}$ in LEED scheme. Developing industrial countries, such as China, have severe indoor particle pollution due to high particle concentrations in outdoor air. However, the control of indoor particle concentrations is not included in green building schemes in such countries. Improvements to these schemes might be needed in the future. 
SVOCs are a group of chemical pollutants with a high residence time indoors. Indoor sources of SVOCs include pesticides, plasticizers, flame retardants, etc. Suspected negative health effects of SVOCs include cancer and endocrine disruption, among others ${ }^{[18]}$. These man-made chemicals are increasingly used in modern built environments. However, in the 31 green building certifications reviewed, control of indoor SVOC concentrations is only mentioned in the KLIMA certification in Austria. In the KLIMA scheme for new office buildings, indoor SVOC sources include paint, sealant, plaster and filler, and wooden materials. Detailed information on how to control indoor SVOC sources is not provided in this scheme. In the KLIMA scheme for new residential buildings, stricter requirements are included for indoor SVOC emission source control. The total SVOC content should not exceed $100 \mu \mathrm{g} / \mathrm{m}^{3}$ in emission test chambers for wooden flooring, floor coverings, and other wooden materials. In addition, the total SVOC content should not exceed $2 \%$ of the weight of flooring coatings. SVOC emission source control in other building materials, as well as measurement of indoor SVOCs, is not required in the KLIMA certification.

\subsection{Different concerns between certifications}

Requirements on IAQ in residential buildings and non-residential buildings are consistent. Differences between new buildings and existing buildings occur because of a variety of requirements on indoor environment design and construction for new buildings and a number of requirements on indoor environment performance for existing buildings. For example, requirements on VOC source control mostly focus on choosing low-VOC-emission materials for new buildings and establishing green cleaning techniques for existing buildings. 
The different concerns between certifications in various countries may due to a number of reasons. For example, laws and regulations on indoor environment vary between countries due to political, economical, and environmental variations. Thus, green building certifications in different countries pay attention to various indoor air pollutants and have different methods to evaluate IAQ. Most commonly, certifications appear as a voluntary complement to national regulations. Some countries include green building directly in their national building regulations. For example, the government of Dubai has listed several green building requirements in its regulation for new residential and non-residential buildings ${ }^{[19]}$. Therefore, when green building specifications or specific indoor pollutant guidelines are defined in national regulations, the accompanying certification does not include such guidelines, as they are already required by law. As such, the comparison between certifications is even more difficult. A similar comparison of national regulations is required to precisely define which indoor air quality criteria are taken into account in green building processes.

\section{Conclusions}

Fifty-five green building schemes in 31 certifications worldwide were reviewed. IAQ is included in all of the certifications as a section that evaluates the health risk of indoor occupants. The global average contribution of IAQ in green building certification is $7.5 \%$. A large variety of compounds are targeted. Some compounds, e.g., ozone, particles, and SVOCs deserve to be considered in a larger number of certifications due to their negative health effects. All of the certifications include ventilation as a way to manage IAQ. Emission source control is included in $77 \%$ of the certifications and is mainly targeted at building material emissions. For existing 
buildings, other emission source control pathways should be more widely considered, such as the reduction of emissions due to cleaning products and cleaning practices. Very few schemes consider this issue, possibly due to the lack of existing tools, standards and labels to characterize the VOC emissions from these products. Indoor air measurement is included in the majority of the certifications (65\%). However, the sampling strategy, the sampling and analytical methods, and the IAQ guidelines used to qualify the results are not often precisely described and appear to be highly variable.

In conclusion, IAQ is taken into account in all the green building certifications considered, and equal emphasis is placed on the two major ways to improve IAQ: emission source control and ventilation. Some possible improvements are identified. This paper has shown the need for transparency to allow the comparison and normalization of green building schemes. Opportunities to harmonize the different approaches used worldwide should be pursued in the future.

\section{Acknowledgements}

The authors thank Dr. Vyt Garnys for his comments on the manuscript.

\section{References}

[1] U.S. Environmental Protection Agency (EPA). Green building basic information. Retrieved Oct. $14^{\text {th }}, 2014$, from http://www.epa.gov/greenbuilding/pubs/about.htm. 
[2] Kibert CJ. Sustainable construction: green building design and delivery. $3^{\text {rd }}$ ed. John Wiley \& Sons, Inc; 2012; ISBN: 978-1-118-33013-5.

[3] Judelson J. The green building revolution. Island Press; 2007; ISBN: 978-1-59726-178-4.

[4] World Commission on Environment and Development. Our common future, chapter 2: towards sustainable development. 1987; Retrieved Nov. $7^{\text {th }}$, 2014, from http://www.undocuments.net/ocf-02.htm.

[5] U.S. Green Building Council (GBC). LEED v4 for building design and construction. 2014; Retrieved Mar. 10 ${ }^{\text {th }}$, 2015, from http://www.usgbc.org/resources/leed-v4-userguide.

[6] BRE Global Ltd. BREEAM UK new construction non-domestic buildings technical manual. 2014; SD5076: 2.0. Retrieved Oct. 15 ${ }^{\text {th }}$, 2014, from http://www.breeam.com.

[7] U.S. Environmental Protection Agency (EPA). Report to Congress on indoor air quality. 1989; Volume 2: EPA/400/1-89/001C. Washington, DC.

[8] Kirchner S. Quality of indoor air, quality of life, a decade of research to breathe better, breathe easier. French Indoor Air Quality Observatory, CSTB Edition. 2013; ISBN: 978-2-86891-5511.

[9] Yu C, Crump D. A review of the emission of VOCs from polymeric materials used in buildings. Building and Environment 1998; 33: 357-374.

[10] Yang X, Cheng Q, Zhang JS, Magee R, Zeng J, Shaw CY. Numerical simulation of VOC emissions from dry materials. Building and Environment 2001; 36: 1099-1107.

[11] Katsumata H, Murakami S, Kato S, Hoshino K, Ataka Y. Measurement of semi-volatile organic compounds emitted from various types of indoor materials by thermal desorption test chamber method. Building and Environment 2008; 43: 378-383. 
[12] World Health Organization (WHO). Guidelines for air quality. 2000; Geneva. Retrieved Oct. $14^{\text {th }}, 2014$, from http://apps.who.int/iris/handle/10665/66537.

[13] ISO 16000-3. Indoor air - Part 3: Determination of formaldehyde and other carbonyl compounds in indoor air and test chamber air - Active sampling method. 2011. Retrieved Oct. $23^{\text {th }}$, 2014, from https://www.iso.org/obp/ui/\#iso:std:iso:16000:-3:ed-2:v1:en.

[14] ISO 16000-6. Indoor air - Part 6: Determination of volatile organic compounds in indoor and test chamber air by active sampling on Tenax TA sorbent, thermal desorption and gas chromatography using MS or MS-FID. 2011. Retrieved Oct. 23 ${ }^{\text {th }}$, 2014, from https://www.iso.org/obp/ui/\#iso:std:iso:16000:-6:ed-2:v1:en.

[15] World Health Organization (WHO). WHO guidelines for indoor air quality: selected pollutants. WHO Regional Office for Europe 2010; ISBN: 978-92-890-0213-4.

[16] World Health Organization (WHO). WHO Air quality guidelines for particulate matter, ozone, nitrogen dioxide and sulfur dioxide: global update 2005: summary of risk assessment. Retrieved Oct. $28^{\text {th }}, 2014$, from http://apps.who.int/iris/handle/10665/69477.

[17] Wisthaler A, Weschler CJ. Reactions of ozone with human skin lipids: sources of carbonyls, dicarbonyls, and hydroxycarbonyls in indoor air. PNAS 2010; 107: 65686575.

[18] Bornehag CG. The shift in human health from infection-related diseases to chronic illnesses and the importance of indoor chemical exposure. The Handbook of Environmental Chemistry 2014; DOI: 10.1007/698_2014_256.

[19] Green building regulations \& specifications. Retrieved Nov. 14 ${ }^{\text {th }}, 2014$, from http://www.dewa.gov.ae/images/greenbuilding_eng.pdf. 